\title{
Ultrastructural basis of enhanced antitumor cytotoxicity of cord blood-derived CTLs: A comparative analysis with peripheral blood and bone marrow
}

\author{
ERIN M. CLARK ${ }^{1}$, DEEPA S. JOSHI ${ }^{2}$, ANDREW B. GRIMM ${ }^{2}$, AVADHUT D. JOSHI ${ }^{1}$, \\ PENG WANG ${ }^{1}$ and SHANTARAM S. JOSHI ${ }^{1}$ \\ ${ }^{1}$ Department of Genetics, Cell Biology and Anatomy, University of Nebraska Medical Center, \\ Omaha, NE 68198, ${ }^{2}$ Millard North High School, Omaha, NE 68154, USA
}

Received April 8, 2010; Accepted May 27, 2010

DOI: 10.3892/ijo_00000713

\begin{abstract}
Umbilical cord blood cells (UCBC) are a rich source of immature immune effector and accessory cells, including dendritic cells. UCBC-derived cytotoxic T lymphocytes (CTLs) generated against human breast cancer or neuroblastoma have shown an increased tumor-specific cytotoxicity compared to peripheral blood (PB)-derived CTLs. The precise mechanism of this increased cytotoxicity is not known. Since dendritic cells (DCs) play a central role in the immunostimulation, we compared the ultrastructure and antigen presenting nature of DCs from UCBC, PB and bone marrow $(\mathrm{BM})$ at various stages of maturation using scanning and transmission electron microscopy as well as fluorescent microscopy to elucidate the mechanism underlying the increased cytotoxicity of UCBC-derived CTLs. DCs were examined for their immunophenotype nuclear morphology, dendritic processes and cytoplasmic endosomal vesicles after $0,3,7$ and 10 days in culture with antigen priming on day 6 . Results showed that there were smaller and more vesicles in UCB-DCs compared to DCs from the other two sources, while the endosomal vesicles in PB-DCs were heterogenous in size. The antigen processing ability of the UCB-DCs showed an increase in antigen-positive endosomes compared to PB-DCs as determined by the fluorescent microscopy. Thus, our results provided the comparative analyses of DCs from cord blood, peripheral blood and bone marrow, and suggested that UCBC-DCs might have better antigen presenting ability leading to increased CTL-mediated antitumor cytotoxicity.
\end{abstract}

Correspondence to: Dr Shantaram S. Joshi, Department of Genetics, Cell Biology and Anatomy, University of Nebraska Medical Center, Omaha, NE 68198, USA

E-mail: ssjoshi@unmc.edu

Key words: dendritic cells, cord blood, ultrastructure, antigen processing, peripheral blood, bone marrow

\section{Introduction}

Initially, for hematopoietic stem cell transplantation and subsequently for cellular immunotherapy there are three major cell sources, namely bone marrow (BM), peripheral blood (PB) and umbilical cord blood (UCB). Among these, $\mathrm{PB}$ has become more commonly used for transplantation and cellular therapy. However, PB is not always a viable cell source, particularly for allogeneic transplantation, due to a lack of HLA-matched donor availability. The third source of hematopoietic and immune cells, UCB, has become a viable alternative source for transplantation because of its several advantages over BM and PB, such as widespread availability, absence of donor risk, absence of donor attrition, low risk of transmissible infectious diseases in the cells, decreased graftversus-host disease (GVHD) without an increased incidence of relapse even in antigen-mismatched situations, and, more importantly, a higher frequency of immune accessory and effector cell precursors such as dendritic cell precursors, natural killer cell precursors and T-cell precursors (1-6). Among these the dendritic cells play an important role in generating CTLs against tumor targets. In addition cord blood cells have been extensively used for other therapeutic purposes including cancer, cardiovascular, diabetes and neurological applications (7-16).

Dendritic cell-based effector cell-mediated cytotoxicity against malignancies has been demonstrated in vitro and in vivo (17-24). Tumor-specific cytotoxic effects of UCBC have also been shown, both in vitro and in vivo (25-30). Head-to-head comparisons of UCB- and PB-derived effector cells suggest that, after stimulation, UCB acquires cytotoxic abilities that equal or surpass that of PB cells. Wang et al (29) and Joshi et al (30) showed that, after priming both UCB-DC and PB-DC with the Her2/neu peptide, cytotoxic T-lymphocytes (CTL) were able to selectively kill Her2/neu expressing cell lines. Their results also showed increased cytotoxic effects of UCB-CTLs over PB-CTLs.

As UCB is becoming an alternative source of cells for cellular therapy, it will be useful to compare DCs obtained from UCB versus DCs obtained from BM and PB. Therefore, in the present study we have compared the ultrastructure of DCs derived from BM, PB and UCB. Our aim was to identify 
and correlate any differences seen in the ultrastructural details of DCs from these three sources to the differences in cytotoxicity noted by us and others. We examined DC topography using scanning electron microscopy (SEM) and analyzed the ultrastructure of DC by transmission electron microscopy (TEM), focusing on cell structures responsible for antigen uptake and presentation. Antigen uptake was further confirmed by fluorescent microscopy. The results of these studies showed an increased dendritic process and endosomal vesicle in DCs derived from UCB compared to PB- or BM-derived DCs.

\section{Materials and methods}

Tumor cell lines. IMR-32, MDA-231 and MDA-453 cancer cells were obtained from the American Type Culture Collection (Rockville, MD). IMR-32 cells were maintained in $25-\mathrm{cm}^{2}$ culture flasks in Minimum Essential Medium supplemented with $10 \%$ fetal bovine serum, $2 \mathrm{mM}$ L-glutamine, $1 \mathrm{mM}$ of sodium pyruvate, $0.1 \mathrm{mM}$ of non-essential amino acids, $100 \mathrm{U} / \mathrm{ml}$ penicillin and $100 \mu \mathrm{g} / \mathrm{ml}$ streptomycin, while MDA 231 and MDA-453 cells were maintained in $25-\mathrm{cm}^{2}$ culture flasks in RF-10 medium (RPMI-1640 medium supplemented with $10 \%$ fetal bovine serum, $2 \mathrm{mM}$ L-glutamine, $100 \mathrm{U} / \mathrm{ml}$ penicillin and $100 \mu \mathrm{g} / \mathrm{ml}$ streptomycin). These cancer cell lines were labeled with chromium-51 $\left(\mathrm{Na}_{2}{ }^{51} \mathrm{CrO}_{4}\right)$ and used as target cells for cytotoxicity assays.

Cell collections. All human cell specimens were collected with informed consent using protocols approved by the Institutional Review Board (IRB) at the University of Nebraska Medical Center (UNMC). In addition to cord blood, normal healthy donor PB and BM samples were also similarly obtained for these studies.

Cord blood cells. Human UCB samples were obtained by the Labor and Delivery Nursing staff. Following the delivery of an infant, the umbilical cord was double clamped, ligated and veni-puncture of the umbilical cord vein was performed using a heparinized syringe prior to expulsion of the placenta. Mononuclear cells from the cord blood were isolated using lymphocyte separation medium (LSM) as described previously (31). The cord blood was diluted with RF-10 medium at a ratio of 1:1 and layered on to 4-to-10 $\mathrm{ml}$ LSM in a $15-\mathrm{ml}$ or 50-ml conical tube. The conical tube containing cord blood was centrifuged for $30 \mathrm{~min}$ at $400 \mathrm{x}$ g using a swinging bucket rotor. After the centrifugation, the mononuclear cells at the interphase were collected, washed, counted and resuspended in medium.

Peripheral blood mononuclear cells. Peripheral blood mononuclear cells were harvested from normal volunteer donors (who received no mobilizing cytokines) using a CobeSpectra apheresis machine as previously described (32). Further purification was done by centrifuging cells obtained from apheresis onto LSM, as described above. The mononuclear cells at the interphase were collected, washed, counted and used for further studies.

Bone marrow cells. Bone marrow cells were harvested from normal BM donors by puncture of the iliac crest under general anesthesia. Aliquots of cells were frozen in liquid nitrogen. For this study, BM cells were thawed and added dropwise to warmed RF-10 medium containing DNAse to prevent clustering of DNA from damaged cells. Cells were pelleted by centrifugation, resuspended in RF-10 and layered over LSM as described above to separate mononuclear cells. Mononuclear cells from UCB, PB and BM were used to generate DCs, as described below.

Her2/neu peptide. MDA-453 human breast cancer cells are known to overexpress the Her2/neu gene (33). Therefore, in order to generate MDA-453-specific CTLs, we primed DCs in vitro with Her2/neu peptide. The Her2/neu-derived peptide E75 (amino acids 369-377, KIFGSLAFL) was synthesized on a peptide synthesizer and analyzed by reverse-phase highperformance liquid chromatography and mass spectrometry to confirm the purity (34).

IMR-32 cell lysate. IMR-32 human neuroblastoma tumor cell-specific CTLs were generated using IMR-32 cell lysate to prime DCs. Fresh IMR-32 tumor cells were suspended in phosphate-buffered saline (PBS) $25 \times 10^{6}$ cells $/ \mathrm{ml}$. The cell suspension was frozen in liquid nitrogen for $15 \mathrm{~min}$ and then thawed in a $37^{\circ} \mathrm{C}$ water bath for $5 \mathrm{~min}$. The freeze thaw cycle was repeated 3 times in rapid succession. The protein concentration of the lysate obtained was quantified by a colorimetric assay at $595 \mathrm{~nm}$ and was stored at $4^{\circ} \mathrm{C}$.

Generation of antigen-pulsed dendritic cells. Briefly, the MNC from umbilical cord blood, peripheral blood or bone marrow were cultured in T-25 tissue culture flasks for $2 \mathrm{~h}$ in RF-10 medium to enrich monocytes. After $2 \mathrm{~h}$, the nonadherent cells were removed and placed into T-25 tissue culture flasks, while the adherent cells were cultured in Prime Complete Growth Medium (PCGM) a dendritic cellspecific medium (GenePrime LLC, Gaithersburg, MD) at a concentration of one million cells $/ \mathrm{ml}$ at $37^{\circ} \mathrm{C}$ in a $5 \% \mathrm{CO}_{2}$ incubator as described previously (27). On the 6th day of the DC culture, either $50 \mu \mathrm{g} / \mathrm{ml}$ of IMR-32 tumor cell lysate or $50 \mu \mathrm{g} / \mathrm{ml} \mathrm{Her} 2 /$ neu peptide was added to the DC culture overnight. After a total of 7 days in culture, cells were harvested and used for CTL generation, immunophenotypic analysis, or for ultrastructural analysis as described below.

Immunophenotypic analysis of PCGM-derived dendritic cells. DCs generated from UCBC and PBC were analyzed for their cell-surface immunophenotypes by flow cytometry using a Becton-Dickinson FACStar PLUS flow cytometer. Two hundred thousand cells were suspended in $100 \mu 1$ of $1 \mathrm{X}$ phosphate-buffered saline (PBS) containing $2 \%$ FBS in a 96-well round-bottomed plate. Cells were incubated for $30 \mathrm{~min}$ on ice with $5 \mu 1$ of fluoroisothiocyanate (FITC)- or phycoerythrin (PE)-labeled antibody specific for the following cell surface markers: CD3, CD14, CD19, CD56, CD80 and CD86 (BD Pharmingen, San Jose, CA). After incubation, the cells were washed twice with $1 \mathrm{X}$ PBS, centrifuged and resuspended in $400 \mu 14 \%$ buffered formalin in PBS for analysis.

Allogeneic-mixed lymphocyte reaction. The DCs generated from UCBC and PB were analyzed for their ability to stimulate proliferation of lymphocytes in an allo-MLR consisting of mononuclear cells from two different healthy donors. The 
mononuclear cells were mixed together in 96-well flatbottomed microtiter plates at a concentration of $10^{5}$ cells/well with a $1: 1$ ratio. DCs were added at a concentration of $5 \%$ of the total cell concentration. Control wells contained $10^{5}$ of each donor mononuclear cells only or with $5 \%$ DC. Cells were incubated for five days at $37^{\circ} \mathrm{C}$ in $5 \% \mathrm{CO}_{2}$. After incubation, $1 \mu \mathrm{Ci}$ of radiolabeled $\left[{ }^{3} \mathrm{H}\right]$ thymidine was added to each well and the plate was incubated for an additional $18 \mathrm{~h}$. After the final incubation period, the cells were harvested onto glassfiber filter-paper disks using a PHD cell harvester (Cambridge Technologies, MA). The filter-paper disks were dried and transferred to plastic scintillation vials containing standard scintillation cocktail. Radioactivity was measured using a liquid scintillation counter (Model no., TRI-CARB 2100TR Packard Instruments, Chicago, IL).

Generation of tumor-specific effector cells. Non-adherent mononuclear cells from UCB and PB were cultured $\left(2 \times 10^{6} / \mathrm{ml}\right)$ in RF-10 medium supplemented with interleukin-2 (IL-2)$(50 \mathrm{U} / \mathrm{ml})$ and incubated at $37^{\circ} \mathrm{C}$ in $5 \% \mathrm{CO}_{2}$ and $95 \%$ air. After 7 days, these cells were co-cultured with autologous mature dendritic cells previously primed with the IMR-32 tumor cell lysate or Her2/neu peptide in vitro. Every 2 days, part of the medium was replenished and IL-2 $(50 \mathrm{U} / \mathrm{ml})$ was added to the co-culture. After co-culturing for 14 days, the cytotoxic ability of the CTLs against IMR-32, or MDA-453 tumor target cells, or MDA-231, an irrelevant control, was evaluated using in vitro chromium-51 release assay as described previously (35).

Cytotoxicity assay. Tumor-specific CTLs obtained from UCBC and $\mathrm{PB}$, as described above, were tested for their cytotoxic ability against ${ }^{51} \mathrm{Cr}$-labeled IMR-32, MDA-231 and MDA-453 tumor cells as described previously (34). The cytotoxicity was calculated using the following formula:

$$
\% \text { Cytotoxicity }=\frac{\text { Experimental CPM }- \text { Spontaneous CPM }}{\text { Maximum CPM }- \text { Spontaneous CPM }} \times 100
$$

Where Experimental CPM = Effector + Target cells; Spontaneous CPM = Target cells + Medium; Maximum CPM $($ total release $)=$ Target cells $+1 \%$ Triton $\mathrm{X}-100$.

Electron microscopy. DCs generated from BM, PB and UCB were analyzed on different days of maturation using transmission and scanning electron microscopy. For TEM, cells were allowed to adhere in T-25 tissue culture flasks, while Thermanox coverslips (NUNC), placed at the bottom of each well of a 6-well plate, were used for SEM. The adherent cell fraction was then cultured in PCGM DC maturation media for 3, 7 or 10 days. Tumor cell lysate was added on day 6 for tumor antigen priming. At each time point, cells were harvested for TEM by gentle scraping from the T-25 flasks followed by centrifugation at $1000 \mathrm{rpm}$ for $5 \mathrm{~min}$. The cell pellets were resuspended in a fixative consisting of $2 \%$ glutaraldehyde, $2 \%$ paraformaldehyde and $0.5 \%$ acrolien in 0.1 M Sorenson's phosphate buffer. For SEM, Thermanox coverslips were removed from the well and placed in fixative. After fixing for at least $1 \mathrm{~h}$, cell pellets and coverslips were washed in 0.1 M Sorenson's phosphate buffer, and post-fixed in $1 \%$ osmium tetroxide. Samples were then washed with buffer and dehydrated in a graded ethanol series. For TEM, after dehydration samples were embedded in araldite. Thin sections were stained with $2 \%$ uranyl acetate and Reynolds lead citrate and examined with a Phillips 410LS TEM operated at $60 \mathrm{Kv}$. For SEM, cell cultures on the Thermanox coverslips were dehydrated, critical point dried, mounted on aluminum specimen stubs and sputter coated with $50 \mathrm{nM}$ of gold/palladium alloy. Microscopy was done on a JEOL T-220A SEM operated at $20 \mathrm{Kv}$.

Fluorescent microscopy. For fluorescent microscopy, DCs were obtained as for EM, and cultured in T-25 tissue culturetreated flasks for 7 days. On day 7 , cells were harvested by scraping, pelleted, resuspended and placed on 4-well chamber slides. Cells were allowed to adhere for $2 \mathrm{~h}$, and then FITClabeled tumor lysate was added. Tumor lysate was prepared as described above, and FITC conjugation was done according to the protocol outlined by Wier (36). Briefly, IMR-32 cells were lysed, and protein concentration was determined by Bradford method. The protein concentration was adjusted to $10 \mathrm{mg} / \mathrm{ml}$ using PBS, and $\mathrm{pH}$ was adjusted to 9.0 with a carbonate-bicarbonate buffer. The protein mixture was chilled in an ice bath, and FITC powder was added (0.05 mg FITC per $1 \mathrm{mg}$ protein). The FITC/protein mixture was left for $18 \mathrm{~h}$ at $4^{\circ} \mathrm{C}$, with gentle stirring. The solution was dialyzed against several changes of $\mathrm{pH}$ 7.0 PBS until dialyzing fluid contained no fluorescence. DCs were incubated with FITClysate for $4 \mathrm{~h}$, washed with PBS, then fixed in $4 \%$ paraformaldehyde and stained with propidium iodide. The slides were then examined using a Zeiss Axioskop2.

Statistical analysis. The statistical significance of the results was determined using the Student's t-test. $\mathrm{p}<0.05$ was considered significant.

\section{Results}

Phenotypic characterization of DCs. DCs were generated from UCBC- and PB-derived adherent mononuclear cells, mainly containing monocytes, by culturing in DC-specific media for 7 days then evaluated for their surface phenotype. There was a significant increase in CD80- and CD86-positive cells, compared to similarly cultured control cells without DC-specific medium. The frequency of other cell types (CD3-positive T-cells, CD14-positive macrophages, CD19positive B-cells and CD56-positive NK cells) was low compared to DCs. Flow cytometric analysis demonstrated no significant difference in expression of any of the cell surface markers studied between UCBC-derived DCs and PBderived DCs (Fig. 1). However, bone marrow-derived DCs contained lesser frequency of CD80-positive cells compared to DCs from peripheral blood or bone marrow. These results demonstrate a typical DC population in cells cultured in PCGM DC-specific medium.

Functional characterization of DCs. In order to confirm the immunostimulation capabilities of DCs, 5\% DCs generated from each cell source were added to allogeneic-mixed lymphocyte reaction generated from each cell source in vitro. As 


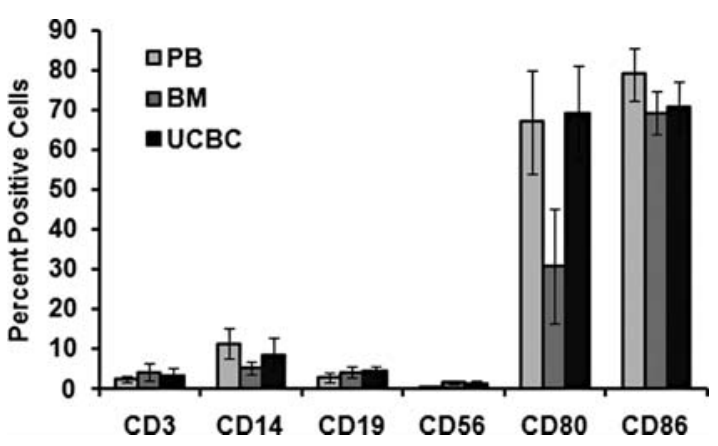

Figure 1. Phenotypes of UCBC- and PB-derived cells after 7 day culture in PCGM medium, as determined by flow cytometry. Values shown represent mean \pm SD of the mean percent positive cells for each of these phenotypic markers derived from these experiments.

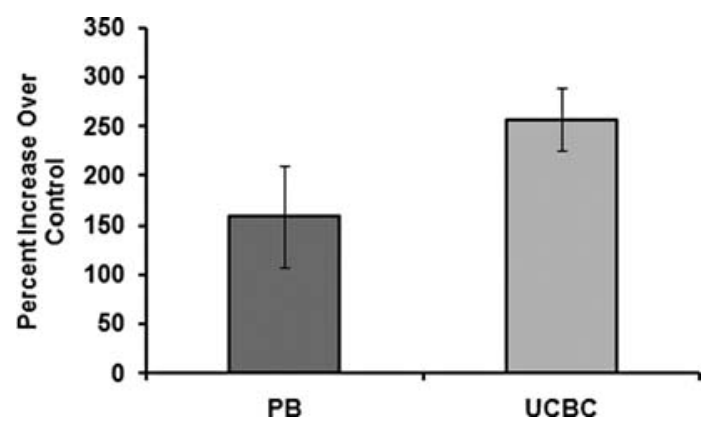

Figure 2. Enhanced allo-MLR response of cells derived from UCBC and PB in the presence of $5 \%$ allogeneic DC. PB or UCBC were cultured in DC media for 7 days, then mixed with lymphocytes from allogeneic donors at a concentration of $5 \%$ of the total cells. The control contained mixed lymphocytes from two donors in the absence of DC. $\left[{ }^{3} \mathrm{H}\right]$-thymidine uptake was measured in counts per minute, and converted to percent increase over control. Values shown represent the percent increase over control cells \pm SE.

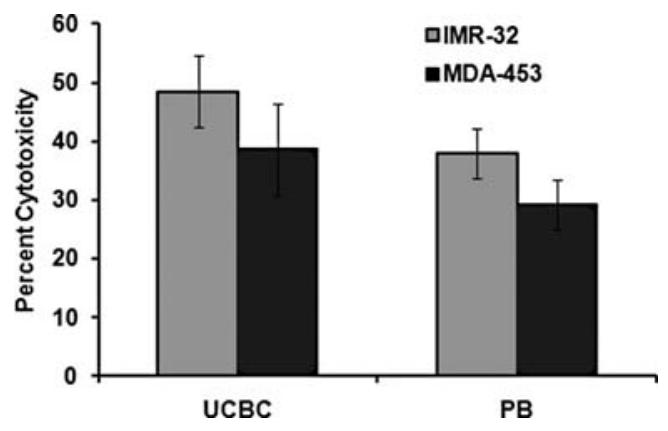

Figure 3. Enhanced antitumor cytotoxicity of UCBC-derived CTLs compared to PB-derived CTLs. CTLs were generated from mononuclear cells from cord blood and peripheral blood against tumor cells as described in the text, then tested for their cytotoxic abilities using a chromium release assay using relevant (solid bars) and irrelevant tumor targets (cross-hatched bars). CTLs generated from UCBC showed a higher cytotoxic effect than CTLs from PB against both MDA-453 human breast cancer and IMR-32 human neuroblastoma.

shown in Fig. 2, the addition of 5\% DC to the UCBC-mixed lymphocyte reaction resulted in a $257 \pm 32 \%$ increase in proliferation, as determined by $\left[{ }^{3} \mathrm{H}\right]$-thymidine uptake, and a $159 \pm 51 \%$ increase in PB proliferation (Fig. 2), when compared to cultures with no addition of DCs. As allo-MLR reactions are usually used to determine immune stimulatory capabilities of DCs, these data indicate the generation of mature, functional DCs after a 7-day culture in PCGM. Once the phenotypic and functional characterization confirmed the generation of DCs, the DCs were then used to generate tumor-specific cytotoxic T lymphocytes from UCB- or PBderived mononuclear cells. In addition DCs were also used for the ultrastructural and immunofluorescent analyses.

Enhanced cytotoxicity of UCBC-derived CTLs. Using the DCs generated as above, tumor-specific CTLs were generated in vitro from both UCBC- and $\mathrm{PB}$-derived mononuclear cells. The tumor-specific cytotoxicities were evaluated against their respective targets, MDA-453 human breast cancer and IMR-32 human neuroblastoma cells and the results are shown in Fig. 3. As shown UCBC-derived CTLs had greater tumor-specific cytotoxicity compared to peripheral bloodderived CTLs against each of the two target tumor cell lines tested. The $48.5 \pm 6.1 \%$ cytotoxicity seen with UCBC was higher than the $37.9 \pm 4.3 \%$ seen with $\mathrm{PB}$-derived CTL against the human neuroblastoma cell line IMR-32 at an effector:target ratio of 50:1. Similarly, UCBC-derived CTLs showed $38.6 \pm 7.8 \%$ cytotoxicity, compared to $29.3 \pm 4.22 \%$ seen with PB-derived CTLs against Her2/neu expressing human breast cancer cell line, MDA-453 tumor target cells. In both studies CTLs showed negligible cytotoxicity to the irrelevant tumor target MDA-231. Thus, there was increased CTL-mediated tumor-specific cytotoxicity with the UCBCderived effector cells compared to PB-derived effector cells. The mechanism for this increased cytotoxicity is not known, but due to the central role of DCs in the development of an antigen-specific immune response, it is fair to hypothesize that the functionality of the DCs generated from each sample may play a role. Therefore, we examined both the ultrastructural and functional characteristics of DCs derived from normal cord blood, peripheral blood and bone marrow.

Surface topography of developing dendritic cells. Banchereau and Steinman (1998) first showed that only mature DCs effectively stimulate the adaptive immune system (37), while peptide-loaded immature DCs induce tolerance (38). Therefore, all DCs used in the generation of cytotoxic cells must be mature antigen presenting cells. In order to determine the maturation status of DCs generated from each cell source, we examined the maturing DCs, on days 0,3, 7 and 10, using scanning electron microscopy (SEM). As demonstrated in Fig. 4, immature DCs traditionally display long, thin dendritic processes which they use to capture antigens in tissues (39). Our analysis revealed that day 0 UCB- and BMderived DCs do indeed display the phenotype expected. On the contrary, day 0 PB-derived DCs seemed to have in the majority of the cells a mature phenotype, showing veils instead of long dendritic processes. The significance of this phenotype is unknown, but warrants further study.

During maturation, DCs undergo many morphological and phenotypical changes. The surface of mature dendritic cells no longer contains the long, thin dendritic processes associated with immature cells, instead adopting a highly veiled phenotype. Day 3 DCs appear to be an intermediate between the day 0 and day 7 cells, as they have fewer 


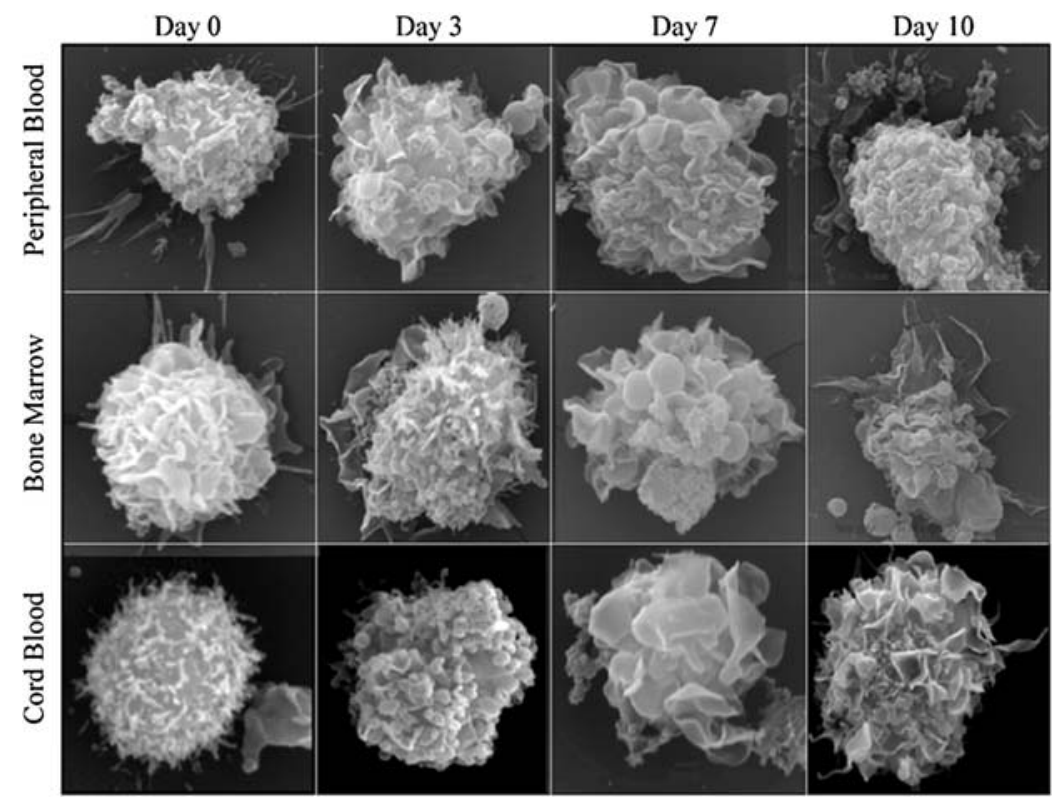

Figure 4. Cell surface ultrastructural topography of DCs derived from BM (top), PB (middle) and UCB (bottom). DCs were grown on Thermanox coverslips in DC-specific medium and analyzed by SEM on days 0,3,7 and 10. Day 0 UCB and BM cells have a characteristically immature appearance, with long, thin dendritic processes. By day 7, all cells had acquired a mature phenotype with dense cytoplasmic veils.

Table I. Ultrastructural analysis of DCs derived from bone marrow, peripheral blood and cord blood. ${ }^{\text {a }}$

\begin{tabular}{llrrr}
\hline & & BMC & PBC & UCBC \\
\hline No. of endosomal vesicles ( \pm SE) & Day 0 & $10.51 \pm 1.7$ & $28.94 \pm 2.8$ & $14.11 \pm 2.3$ \\
& Day 7 & $64.44 \pm 5.5$ & $23.78 \pm 2.8$ & $26.45 \pm 3.4$ \\
Nuclear size in microns ( \pm SE) & Day 0 & $5.56 \pm 0.5$ & $4.69 \pm 0.2$ & $4.5 \pm 0.2$ \\
& Day 7 & $8.31 \pm 0.5$ & $5.77 \pm 0.3$ & $6.14 \pm 0.3$ \\
No. of dendritic processes ( \pm SE) & Day 0 & $12.46 \pm 0.8$ & $15.90 \pm 0.8$ & $19.53 \pm 1.1$ \\
& Day 7 & $14.15 \pm 1.1$ & $7.92 \pm 0.7$ & $12.06 \pm 1.0$ \\
\hline
\end{tabular}

aComparison of day 0 and day 7 ultrastructure of DC derived from each of the cell sources for their ultrastructure, including number of endosomal vesicles, nuclear size and number of dendritic processes. The values shown represent mean \pm SE of 100 cells from each of the three cell sources.

processes but have started to acquire cytoplasmic veils. Day 7 cells have been exposed to antigen in the form of a tumor cell lysate and show a fully mature phenotype with dense cytoplasmic veils and a complete absence of dendritic processes (38-40). We also witnessed DC/lymphocyte interaction in many of these cells. Day 10 DCs have lost the densely veiled appearance, indicating that these cells have passed their prime maturation point. These morphological and surface topographical features have been evaluated in $\sim 50-100$ cells from at least 3 different donor-derived cells

Ultrastructure of developing dendritic cells. In addition to surface topographical analyses using scanning electron microscopy, DCs derived from UCBC, PB and BM from normal donors were also evaluated for their cellular ultrastructure using transmission electron microscopy (TEM). Once antigens are captured by the maturing DCs, the captured antigenic molecules will be digested and presented to $\mathrm{T}$ lymphocytes. This process occurs in the cytoplasmic endosomes. Therefore, as a next logical step, we examined the ultrastructure of these developing DCs generated from each cell source. As the primary function of DCs is antigen uptake and processing, we examined the number of dendritic processes and endosomal vesicles on mature and immature DCs. Fig. 5 shows representative cells from each cell source at each time point; days 0, 3, 7 and 10 after in culture. Day 3 DCs showed generally more dendritic processes and fewer endosomal vesicles than day 7 DCs. Day 7 DCs were also larger.

In order to understand the ultrastructural details of the developing DCs, the number of dendritic processes, nuclear size and number of endosomal vesicles were determined by examining 50-100 cells from each source at each time point. As is summarized in Table I, there was a significant difference 


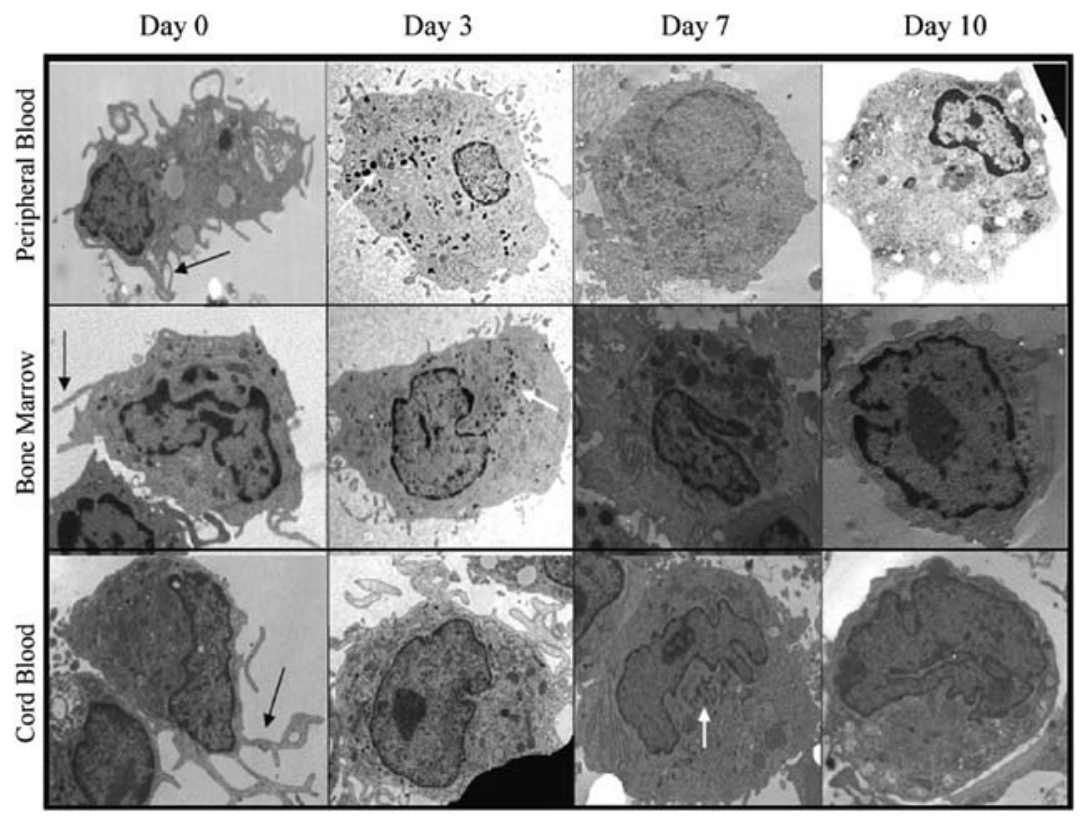

Figure 5. Transmission electron microscopy of DCs generated from BM (top) PB (center) and UCB (bottom). Cells were cultured in tissue culture flasks and harvested on days $0,3,7$ and 10 (left to right). Photographs are representative of at least 60 cells examined. Dendritic processes (black arrows) and endosomal vesicles (white arrows) were counted in each cell. Summary of these findings are presented in Table I.
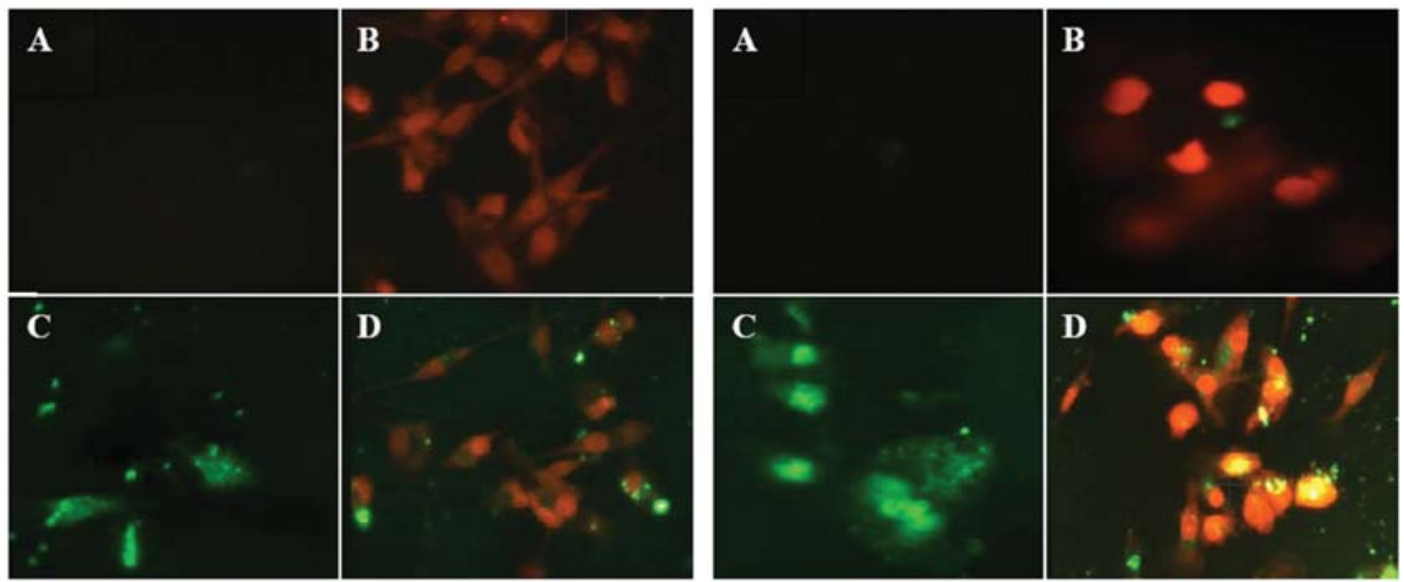

Figure 6. Representative photographs of DCs as viewed under fluorescent microscopy. DCs were incubated with media alone, (A) propidium iodide alone, (B) FITC-labeled tumor cell lysate alone, (C) or a combination of PI- and FITC-labeled tumor cell lysate. Green punctuate staining within the cytoplasm was attributed to endosomes containing FITC-labeled tumor cell lysate. The number of FTIC-labeled endosomes were counted in each DC that of 100 positive cells.

in the number of dendritic processes seen on the surface of day 3 cells between cell sources. The number of dendritic processes in day $3 \mathrm{UCB}$ DC, at $19.5 \pm 1.1$, was significantly higher than both PB $(15.9 \pm 0.8)$ and BM $(12.5 \pm 0.8)(\mathrm{p}<0.05)$. By day 7, DC from UCB and PB showed a decrease in the number of dendritic processes, which is consistent with a mature phenotype, and correlates with what was seen by SEM. The number of dendritic processes in BM remained relatively unchanged. The number of processes in UCB was still significantly higher than PB or BM $(\mathrm{p}<0.05)$.

We also observed a significant $(\mathrm{p}<0.05)$ difference in the number of endosomal vesicles in the PB-DCs $(28.9 \pm 2.8)$ on day 0 compared to UCB-DCs $(14.1 \pm 2.3)$ and BM-DCs $(10.5 \pm 1.7)$. While this is unexpected, as day 3 samples have not yet been antigen primed and therefore should not have extensive endosomal vesicles, it correlates with the DC phenotype seen in the day 3 samples by SEM in Fig. 4. By day 7, UCB- and BM-derived DCs had a significant increase in the number of endosomal vesicles in their cytoplasm (64.4 \pm 5.5 , and 26.5 \pm 3.4 , respectively, $p<0.05)$, while the number of vesicles in PB-derived DCs had decreased slightly, to $23.8 \pm 2.8$. We also noted a difference in nuclear size from day 0 to day 7 DCs, with the average nuclear size increasing as the DCs matured. This has been seen by others $(39,41)$, and is due to an increase in cell size as a whole.

Antigen processing in the dendritic cells. In order to confirm whether the endosomal vesicles present in TEM had a role in 
antigen processing, we examined day 7 DCs derived from PB and UCB using fluorescent microscopy with fluorescent dyeconjugated tumor cell lysate. The use of a FITC-labeled tumor cell lysate enabled us to localize and count the number of FITC-positive vesicles, which appeared as strongly fluorescent punctuate staining in the cytoplasm of the cells (Fig. 6). We also used propidium iodide (PI) as a nuclear counterstain, taking advantage of its ability to intercalate DNA. As FITC and PI fluoresce on the same wavelength, it is possible to directly count the number of FITC-labeled endosomes in each cell. Cells were counted only if they contained FITClabeled endosomes, that is, only cells that had taken up the antigen were counted. These FITC-positive cells represented $57 \%$ of the total cell population in UCBC, and $49 \%$ of the total cell population in PB. Of the DCs that contained FITC-

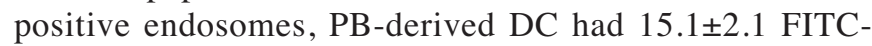
positive endosomes per cell, while UCB-derived DC had $19.2 \pm 1.2(\mathrm{p}<0.05)$.

\section{Discussion}

In this study we have compared the ultrastructural properties of DCs derived from peripheral blood, bone marrow and umbilical cord blood. As the primary function of DCs is antigen uptake and presentation to T-cells, we focused on those structures that are integral to this function, the dendritic processes and the endosomal vesicles. Cells derived from the three major cell sources have varying levels of immaturity, as evidenced by the differences in repopulation assays (42). PB is currently the source of choice for immunotherapy in clinical trials, although the response rates in these trials are not as high as was initially hoped. It has been shown that UCB effector cells can be stimulated in vitro to acquire nonspecific effector cytotoxicity equal to or higher than that of PB (43), as well as specific antitumor effects that surpass PBderived cytotoxic cells (28-30). We have shown that CTLs generated from UCBC have superior antitumor cytotoxic effects than PB-derived CTLs against two different target tumor cell lines. The generation of CTLs is fairly complex, involving DCs and T-cell interaction. In order to prevent induction of tolerance, DCs must be effectively matured prior to antigen presentation, including upregulation of costimulatory molecules. Our method of generation of DCs has been shown to generate mature DCs as evidenced by the presence of co-stimulatory molecules on the cell surface when measured by flow cytometry (29), but the direct comparison of ultrastructural characteristics of the DCs derived from different sources has not been reported so far. Therefore, we examined and compared DCs derived from BM, PB and $\mathrm{UCB}$ in order to determine whether differences in the ultrastructure of these cells could be responsible for the varied cytotoxicity.

Scanning electron microscopic analysis revealed that, while day 0 BM-DCs and UCB-DCs cells displayed the anticipated immature morphology, day 0 PB cells displayed a mature phenotype. This phenotype was prevalent in a large majority of the cells examined, so it does not appear to be an artifact. This is a puzzling finding, as the current immunological dogma is that immature DCs reside in the periphery where they capture antigen. In response to a 'danger signal', these cells mature and migrate to the lymph node. According to this, there should be very few, if any, mature DCs in the peripheral blood. We plan to determine the significance of these cells using more advanced biochemical and immunological methods. Other than this anomaly, DCs from each source followed the expected progression of phenotype, supported by others (41). Immature DCs displayed long, thin dendritic processes, day 3 cells were a combination of veils and processes, mature DC displayed dense cytoplasmic veils on the cell surface, and day 10 cells were sparsely covered in veils. The purpose of the cytoplasmic veils seems to be increased surface area for T-cell stimulation; Setum et al showed that antigen is heavily presented on these veils (44). In many instances we witnessed DC/lymphocyte interaction, where the lymphocyte was partially surrounded by the veils. As there was no antigen priming until day 6, the appearance of thin veils on day 3 cells may be due to the intake and presentation of peptides present in the fetal bovine serum used in the media. Our laboratory uses day 7 DCs to prime CTLs, an approach supported by the results of this SEM, as it appears that the most mature and effective antigen presenting cells were present on day 7 .

Ultrastructural analyses using TEM allowed us to correlate the phenotypic DC maturation stages seen in SEM with the cell surface and intracellular changes in DCs, namely dendritic processes and endosomal vesicles, before and after antigen binding. As dendritic processes are used by DCs to sample their microenvironment, it is feasible that the increased number of processes exhibited by day 3 UCB-derived DCs when compared to PB-derived DCs may correlate with the increase in endosomes seen on day 7 . The decrease in dendritic processes seen on day 7 is consistent with the accepted process of DC maturation. The number of endosomes in PB decreased from day 3 to day 7 , although this may be explained by the appearance of a mature phenotype in day 0 SEM.

The use of fluorescent microscopy to visualize antigen uptake has allowed us to quantitate the uptake capabilities of day 7 UCBC-derived DCs compared to day 7 PBderived DCs. Of the DCs that effectively endocytosed the FITC-labeled tumor cell lysate, those derived from UCBC showed a significantly higher number of FITC-positive endosomes. As one of the main functions of DCs is to process and present antigen, the increase in tumor lysate-positive endosomes may explain in part the mechanism of increased cytotoxicity seen in the UCBC-derived CTLs. Further analysis of the DC/T-cell interaction such as cell to cell binding, expression of co-stimulatory molecules, cytokine release and T-cell signaling is needed to validate the significance of this finding.

In conclusion, the development and maturation of DC precursors into functional DCs is similar from day 0 to day 10 , regardless of the cell source. Ultrastructural analyses suggested that the increased cytotoxic effects shown by $\mathrm{UCBC}$ in vitro may be attributed to the increased antigen uptake capability of UCBC-derived DCs. This needs to be further investigated with in depth analyses. While PB-derived DCs are used in the clinical setting, the results of this study suggest that UCBC-derived DCs may also be an acceptable cell source for the generation of tumor-specific cellular therapy to treat malignancy. 


\section{Acknowledgements}

We would like to thank Mr. Tom Bargar of the Electron Microscopy core facility for his expertise in the preparation and examination of the electron micrographs. We would also like to thank Dr Gordon Todd for the use of his fluorescent microscope, and Ms. Ruth Olson for her help in preparing this manuscript.

\section{References}

1. Apperley JF: Umbilical cord blood progenitor cell transplantation. The International Conference Workshop on Cord Blood Transplantation. Bone Marrow Transplant. 14: 187-196, 1994.

2. Broxmeyer HE, Gluckman E, Auerbach A, Douglas GW, Friedman H, Cooper S, et al: Human umbilical cord blood: a clinically useful source of transplantable hematopoietic stem/ progenitor cells. Int J Cell Cloning 8 (Supp. 1): S76-S91, 1990.

3. Gluckman E, Broxmeyer HA, Auerbach AD, Friedman HS, Douglas GW, Devergie A, et al: Hematopoietic reconstitution in a patient with Fanconi's anemia by means of umbilical-cord blood from an HLA-identical sibling. N Engl J Med 321: 1174-1178, 1989.

4. Schoemans H, Theunissen K, Maertens J, Boogaerts M, Verfaillie $\mathrm{C}$ and Wagner J: Adult umbilical cord blood transplantation: a comprehensive review. Bone Marrow Transplant 38: 83-93, 2006.

5. Theilgaard-Monch K, Raaschou-Jensen K, Palm H, et al: Flow cytometric assessment of lymphocyte subsets, lymphoid progenitors, and hematopoietic stem cells in allogeneic stem cell grafts. Bone Marrow Transplant 28: 1073-1082, 2001.

6. Gluckman E and Rocha V: Cord blood transplantation: state of the art. Hematologica 94: 451-454, 2009.

7. Reimann V, Creutzig U and Kogler G: Stem cells derived from cord blood in transplantation and regenerative medicine. Dtsch Arztebl Int 106: 831-836, 2009

8. Schlechta B, Wiedermann D, Kittinger C, Jandrositz A, Bonaros NE, Humer JC, Preisegger K and Kocher AA: Ex-vivo expanded umbilical cord blood stem cells retain capacity for myocardial regeneration. Circ J 74: 188-194, 2010.

9. Roszek K and Komoszynski M: Regulation and direction of umbilical cord blood stem cells differentiation and their therapeutic application (Review). Postepy Hig Med Dosw (online) 62: 660-667, 2008.

10. Yu G, Borlongan CV, Stahl CE, Yu SJ, Bae E, Yang T, et al: Transplantation of human umbilical cord blood cells for the repair of myocardial infarction. Med Sci Monit 14: RA163-RA172, 2008.

11. Ichim TE, Solano F, Brenes R, Glenn E, Chan J, Chan K, et al: Placental mesenchymal and cord blood stem cell therapy for dilated cardiomyopathy. Reprod Biomed Online 16: 898-905, 2008 .

12. Tse W, Bunting KD and Laughlin MJ: New insights into cord blood stem cell transplantation. Curr Opin Hematol 15: 279-284, 2008.

13. Haller MJ, Viener HL, Wasserfall C, Brusko T, Atkinson MA and Schatz DA: Autologous umbilical cord blood infusion for type 1 diabetes. Exp Hematol 36: 710-715, 2008.

14. Burt RK, Loh Y, Pearce W, Beohar N, Barr WG, Craig R, et al: Clinical applications of blood-derived and marrow-derived stem cells for nonmalignant diseases. JAMA 299: 925-936, 2008.

15. Tse WW, Zang, SL, Bunting KD and Laughlin MJ: Umbilical cord blood transplantation in adult myeloid leukemia. Bone Marrow Transplant 41: 465-472, 2008.

16. Harris DT and Rogers I: Umbilical cord blood: a unique source of pluripotent stem cells for regenerative medicine. Curr Stem Cell Res Ther 2: 301-309, 2007.

17. Escobar A, López M, Serrano A, Ramirez M, Pérez C, Aguirre A, et al: Dendritic cell immunizations alone or combined with low doses of interleukin-2 induce specific immune responses in melanoma patients. Clin Exp Immunol 142: 555-568, 2005.

18. Banchereau J, Dhodapkar M, Connolly J, Finholt JP, Klechevsky E, Blanck JP, et al: Immune and clinical outcomes in patients with stage IV melanoma vaccinated with peptidepulsed dendritic cells derived from $\mathrm{CD} 34^{+}$progenitors and activated with type I interferon. J Immunother 28: 505-516, 2005.
19. Comoli P, Pedrazzoli P, Maccario R, Basso S, Carminati O, Labirio M, et al: Cell therapy of stage IV nasopharyngeal carcinoma with autologous Epstein-Barr virus-targeted cytotoxic $\mathrm{T}$ lymphocytes. J Clin Oncol 23: 8942-849, 2005.

20. Straathof KC, Bollard CM, Popat U, Huls MH, Lopez T, Morriss MC, et al: Treatment of nasopharyngeal carcinoma with Epstein-Barr virus-specific T lymphocytes. Blood 105: 1898-1904, 2005

21. Schwartz JD and Beutler AS: Therapy for unresectable hepatocellular carcinoma: review of the randomized clinical trials-II: systemic and local non-embolization-based therapies in unresectable and advanced hepatocellular carcinoma. Anticancer Drugs 15: 439-452, 2004.

22. Lee WC, Wang HC, Hung CF, Huang PF, Lia CR and Chen MF: Vaccination of advanced hepatocellular carcinoma patients with tumor lysate-pulsed dendritic cells: a clinical trial. J Immunother 28: 496-504, 2005.

23. Mu LJ, Kyte JA, Kvalheim G, Aamdal S, Dueland S, Hauser M, et al: Immunotherapy with allotumour mRNA-transfected dendritic cells in androgen-resistant prostate cancer patients. $\mathrm{Br}$ J Cancer 93: 749-756, 2005.

24. Waeckerle-Men Y, Uetz-von Allmen E, Fopp M, von Moos R, Bahme C, Schmid H-P, et al: Dendritic cell-based multi-epitope immunotherapy of hormone-refractory prostate carcinoma. Cancer Immunol Immunother 55: 1524-1533, 2006.

25. Harris DT, LoCascio J and Besencon FJ: Analysis of the alloreactive capacity of human umbilical cord blood: implications for graft-versus-host disease. Bone Marrow Transplant 14: 545-553, 1994.

26. Joshi SS, Babushkina-Patz NN, Verbik DJ, Gross TG, Tarantolo SR, Kuszynski CA, et al: Antitumor activity of human umbilical cord blood cells: A comparative analysis with peripheral blood and bone marrow cells. Int J Oncol 13: 791-799, 1998.

27. Joshi SS, Vu E, Lovgren TR, Lorkovic M, Patel W, Todd GL, et al: Comparison of phenotypic and functional dendritic cells derived from human umbilical cord blood and peripheral blood mononuclear cells. J Hematother Stem Cell Res 11: 337-347, 2002.

28. Lovgren TR, Tarantolo SR, Evans C, Kuszynski CA and Joshi SS: Enhanced in vitro and in vivo cytotoxicity of umbilical cord blood cells against human breast cancer following activation with IL-15 and colony stimulating factors. In Vivo 16: 541-550, 2002.

29. Wang P, Munger CM, Joshi AD, Pirruccello SJ and Joshi SS: Cytotoxicity of cord blood derived Her2/neu-specific cytotoxic T lymphocytes against human breast cancer in vitro and in vivo. Breast Cancer Res Treat 83: 15-23, 2004

30. Joshi AD, Clark EM, Wang P, Munger CM, Hegde GV, Sanderson S, et al: Immunotherapy of human neuroblastoma using umbilical cord blood-derived effector cells. J Neuroimmune Pharmacol 2: 201-212, 2007.

31. Verbik DJ, Jackson JD, Pirruccello SJ, Patil KD, Kessinger A and Joshi SS: Functional and phenotypic characterization of human peripheral blood stem cell harvests: a comparative analysis of cells from consecutive collections. Blood 85 : 1964-1970, 1995.

32. Kessinger A and Armitage JO: The evolving role of autologous peripheral stem cell transplantation following high-dose therapy for malignancies. Blood 77: 211-213, 1991.

33. Kraus MH, Popescu NC, Amsbaugh SC and King CR: Overexpression of the EGF receptor-related proto-oncogene erbB-2 in human mammary tumor cell lines by different molecular mechanisms. EMBO J 6: 605-610, 1987.

34. Brossart P, Stuhler G, Flad T, Stevanovic S, Rammensee HG, Kanz L, et al: Her2/neu-derived peptides are tumor associated antigen expressed by human renal cell and colon carcinoma lines and are recognized by in vitro induced specific cytotoxic $\mathrm{T}$ lymphocytes. Cancer Res 15: 732-738, 1998.

35. Munger CM, Vose JM and Joshi SS: Dendritic cell-based therapy for mantle cell lymphoma. Int J Oncol 28: 1337-1343, 2006.

36. Weir DM: Handbook of Experimental Immunology. 4th edition. Blackwell Scientific, Boston, 1986.

37. Banchereau J and Steinman RM: Dendritic cells and the control of immunity. Nature 392: 245-252, 1998.

38. Probst HC, Lagnel J, Kollias G and van den Broek M: Inducible transgenic mice reveal resting dendritic cells as potent inducers of $\mathrm{CD}^{+} \mathrm{T}$ cell tolerance. Immunity 18: 713-720, 2003.

39. Cella M, Sallusto F and Lanzavecchia A: Origin, maturation and antigen presenting function of dendritic cells. Curr Opin Immunol 9: 10-16, 1997. 
40. Shutt DC, Daniels KJ, Caroloan EJ, Hill AC and Soll DR: Changes in the motility, morphology, and F-actin architecture of human dendritic cells in an in vitro model of dendritic cell development. Cell Motil Cytoskeleton 46: 200-202, 2000.

41. Verdijk P, de Ru AH, Hensbergen PJ, Mizuno K, Koerten HK, Koning F, et al: Morphological changes during dendritic cell maturation correlate with cofilin activation and translocation to the cell membrane. Eur J Immunol 34: 156-164, 2004.

42. Theunissen $\mathrm{K}$ and Verfaillie CM: A multifactorial analysis of umbilical cord blood, adult bone marrow and mobilized peripheral blood progenitors using the improved ML-IC assay. Exp Hematol 33: 165-172, 2005 .
43. Wang JC, Doedens $M$ and Dick JE: Primitive human hematopoietic cells are enriched in cord blood compared with adult bone marrow or mobilized peripheral blood as measured by the quantitative in vivo SCID-repopulating cell assay. Blood 89: 3919-3924, 1997

44. Setum CM, Serie JR and Hegre OD: Dendritic cell/lymphocyte clustering: morphologic analysis by transmission electron microscopy and distribution of gold-labeled MHC class II antigens by high-resolution scanning electron microscopy. Anat Rec 235: 285-295, 1993. 